\title{
Herbicidal characteristics of MT-147, a novel glycol benzyl ether as a graminicide in paddy rice
}

\author{
Takeshi KaKimoto, ${ }^{\dagger}$ Kangetsu Hirase, ${ }^{*}$ Fumiaki KoIzumi and Kiyoshi AraI \\ Agrochemicals Group, Functional Chemicals Laboratory, R\&D Center, Mitsui Chemicals, INC., \\ 1144 Togo, Mobara, Chiba 297-0017, Japan \\ ${ }^{\dagger}$ Agrochemicals Group, Functional Chemicals Laboratory, R\&D Center, Mitsui Chemicals, INC., \\ 30 Asamuta-machi, Oomuta, Fukuoka 836-8610, Japan
}

(Received June 29, 2006; Accepted August 3, 2006)

\begin{abstract}
The herbicidal performance of MT-147, (2R,3S,3aS,9bR)-2-ethyl-3-(2-fluorobenzyloxy)-6,7-methylenedioxy$3,3 a, 5,9 b$-tetrahydro- $2 H$-furo[3,2-c][2]benzopyran, was examined as a graminicide for paddy rice. MT-147 completely controlled barnyardgrass from pre-emergence up to the 2.0 -leaf stage at $300 \mathrm{~g}$ a.i./ha by submerged application; however, the efficacy decreased as the leaf stage proceeded further. The herbicidal activity of MT-147 was not influenced by water depth, but it was slightly affected by the seeding depth of barnyardgrass, the activity being lower when the seeding depth was deeper. MT-147 had no phytotoxicity to transplanted rice at $300 \mathrm{~g}$ a.i./ha but phytotoxicity was observed when rice seedlings were placed on the soil surface and the roots were exposed to water. Bromobutide remarkably increased the herbicidal activity of MT-147 against barnyardgrass. In this study, it was revealed that a novel 3,3a,5,9b-tetrahydro- $2 H$-furo[3,2-c][2]benzopyran, MT-147, has excellent herbicidal activity against barnyardgrass, and its activity was enhanced by bromobutide. C Pesticide Science Society of Japan
\end{abstract}

Keywords: 3,3a,5,9b-tetrahydro-2H-furo[3,2-c][2]benzopyran, MT-147, bromobutide, barnyardgrass, transplanted rice.

\section{Introduction}

Chiral 3,3a,5,9b-tetrahydro-2H-furo[3,2-c][2]benzopyrans (TFBs) were synthesized and some of them were found to be herbicidally active against annual paddy weeds through intensive structure-activity relationship studies. ${ }^{1-5)}$ These compounds were synthesized from D-glucose, which was used as a natural chiral source. ${ }^{1-5)}$ This was the result of a series of studies based on the findings that certain benzyl ethers (e.g. cinmethylin) had herbicidal activity. ${ }^{3)}$ Further investigation revealed that $(2 R, 3 S, 3 \mathrm{a} S, 9 \mathrm{~b} R)$-2-ethyl-3-(2-fluorobenzyloxy)6,7-methylenedioxy-3,3a,5,9b-tetrahydro- $2 \mathrm{H}$-furo[3,2c][2]benzopyran (MT-147) was the one of the most active compounds and seemed to have suitable herbicidal characteristics as a graminicide for paddy rice (Oryza sativa L.). ${ }^{1)}$ Barnyardgrass (Echinochloa crus-galli L.) is one of the dominant annual weed species in paddy rice fields in Japan. ${ }^{6)} \mathrm{Al}-$

\footnotetext{
* To whom correspondence should be addressed.

E-mail: kangetsu.hirase@mitsui-chem.co.jp

Published online September 14, 2006

(C) Pesticide Science Society of Japan
}

though preliminary tests indicated that MT-147 was a possible herbicidal agent to control barnyardgrass, detailed characterization of this compound has not been accomplished. It is useful to evaluate herbicidal activity under different conditions in order to understand herbicidal characteristics because herbicidal activity and phytotoxicity usually fluctuate depending on environmental and cultural factors. It is known that herbicidal activity and phytotoxicity usually change at the leaf stage of target plants, ${ }^{7-10)}$ water depth $^{8)}$ and transplanting depth. ${ }^{9,11)}$ In this study, the effect of several test conditions on the herbicidal activity of MT-147 was examined to clarify the characteristics of this compound.

Herbicides registered for paddy rice in Japan are mostly combinations consisting of two to five active ingredients. It is important to examine the compatibility of certain herbicides with other compounds to develop effective combination products. During our preliminary investigation, bromobutide was found to increase the herbicidal activity for MT-147; therefore, the effects of this compound on the herbicidal activity of MT-147 are also reported here. 

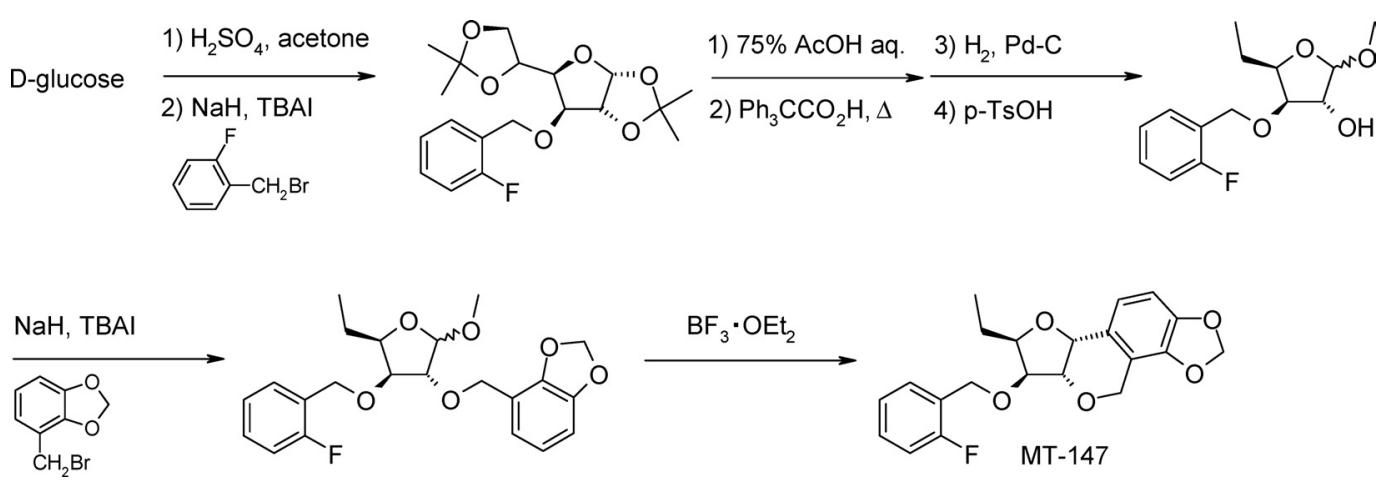

Fig. 1. Synthesis of MT-147.

\section{Materials and Methods}

\section{Chemicals}

MT-147 was synthesized from D-glucose through 8 steps according to the reported procedure (Fig. 1). ${ }^{1-3)}$ Yield: $80 \%$, Colorless crystal, Mp: $82.1-83.0^{\circ} \mathrm{C},{ }^{1} \mathrm{H}-\mathrm{NMR} \delta_{\mathrm{H}}\left(\mathrm{CDCl}_{3}\right)$ : $0.89(3 \mathrm{H}, \mathrm{t}, J=7.3 \mathrm{~Hz}), 1.74(2 \mathrm{H}, \mathrm{dq}, J=7.3,7.3 \mathrm{~Hz}), 4.03$ $(1 \mathrm{H}, \mathrm{d}, J=3.7 \mathrm{~Hz}), 4.14(1 \mathrm{H}, \mathrm{d}, J=3.7 \mathrm{~Hz}), 4.28(1 \mathrm{H}, \mathrm{d}, J=3.7$ $\mathrm{Hz}), 4.52(1 \mathrm{H}, \mathrm{d}, J=11.7 \mathrm{~Hz}), 4.64(1 \mathrm{H}, \mathrm{d}, J=11.7 \mathrm{~Hz}), 4.80$ $(1 \mathrm{H}, \mathrm{d}, J=11.7 \mathrm{~Hz}), 4.84(1 \mathrm{H}, \mathrm{d}, J=3.7 \mathrm{~Hz}), 4.88(1 \mathrm{H}, \mathrm{d}$, $J=11.7 \mathrm{~Hz}), 5.93-5.96(2 \mathrm{H}, \mathrm{m}), 6.79(1 \mathrm{H}, \mathrm{d}, J=8.1 \mathrm{~Hz})$, 7.00-7.49 (5H, m). $[\alpha]_{25}^{\mathrm{D}}=-57.4^{\circ}$ (c 0.8 , ethanol). Elemental analysis: Found: C, 67.90; H, 5.54\%. Calcd. for $\mathrm{C}_{21} \mathrm{H}_{21} \mathrm{FO}_{5}$ : C, 67.73; H, 5.68\%. Bromobutide (96\% in purity) and mefenacet ( $97 \%$ in purity) were synthesized at Functional Chemicals Laboratory, Mitsui Chemicals, Inc.

\section{Evaluation of herbicidal activity}

Approximately 50 seeds of barnyardgrass were sown in Mobara soil [sandy loam, total carbon, $2.0 \%$; total nitrogen, $0.17 \%$; pH $5.6\left(\mathrm{H}_{2} \mathrm{O}\right)$; CEC, $10.8 \mathrm{me} / 100 \mathrm{~g}$; coarse sand, $19.4 \%$; fine sand, $61.5 \%$; silt, $7.2 \%$; clay, $11.9 \%$ ] in $200 \mathrm{~cm}^{2}$ Wagner pots. The plants were grown in a greenhouse at a temperature ranging between $20^{\circ} \mathrm{C}$ (night) and $30^{\circ} \mathrm{C}$ (day) under natural light conditions. Unless otherwise indicated, the seeds were sown at $0.5 \mathrm{~cm}$ deep, and acetone solutions of MT147 with or without bromobutide (900 g a.i./ha) were applied to the paddy water $(3 \mathrm{~cm}$ deep) with pipettes at the 2.0-leaf stage. The volume of acetone applied was 1 to $2 \mathrm{ml} / \mathrm{pot}$ throughout this study. No water leakage occurred during the tests. These plants were kept under the same conditions as above for 3 weeks, and herbicidal activity was visually evaluated by the following scale: 0 (no activity) to 100 (complete kill).

\section{Evaluation of phytotoxicity}

Seedlings of rice (Oryza sativa L., cv. Koshihikari) at the 2.5leaf stage were transplanted in Mobara soil in $200 \mathrm{~cm}^{2}$ Wagner pots in a greenhouse. The transplanting depth was 0 (roots were located on the soil surface), 1 and $2.5 \mathrm{~cm}$. An acetone solution of MT-147 was applied to $3 \mathrm{~cm}$-deep water one day after transplanting and plant injury was visually evaluated by the following scale: 0 (no activity) to 100 (complete kill) 3 weeks after application. Other experimental conditions were the same as described above.

\section{Effect of contact period}

Plant materials were prepared as described above, and an acetone solution of MT-147 was applied to the water at a dosage of $300 \mathrm{~g}$ a.i./ha when the barnyardgrass was at the 2.0-leaf stage. An acetone solution of bromobutide (500 g a.i./ha) and mefenacet (1000 g a.i./ha) was also applied in the same manner. No water leakage occurred during the tests. The plants were transferred to a water culture [half-strength Kasugai's nutrient solution ${ }^{12)}$ ] without these compounds from pots 1, 2, 4 and 8 days after MT-147 application. The roots were thoroughly washed with deionized water before transfer. Plants treated with acetone only were transferred to water culture in the same manner as a control.

Herbicidal activity was visually evaluated in the water culture 18 days after application with the same scale as described above. Each test in this study was conducted with three to four replications.

\section{Results and Discussion}

\section{Herbicidal activity on barnyardgrass}

With respect to the herbicidal spectrum, MT-147 indicates activity against some annual broadleaved weeds such as Monochoria sp. and Lindernia sp., in addition to barnyardgrass (data not shown). However, MT-147 shows no herbicidal activity against sedge weeds such as Scirpus juncoides or perennial broadleaved weeds such as Sagittaria pygmaea and relatively low activity against upland weeds. Therefore, MT-147 seems to have a herbicidal spectrum suitable as a graminicide in paddy rice, and we focused this study on its herbicidal properties in regard to barnyardgrass.

First of all, the effects of the leaf stage of barnyardgrass, and seeding depth on the herbicidal activity of MT-147 were examined. The leaf stage of barnyardgrass drastically affected the herbicidal efficacy of MT-147 (Fig. 2). When applied at 


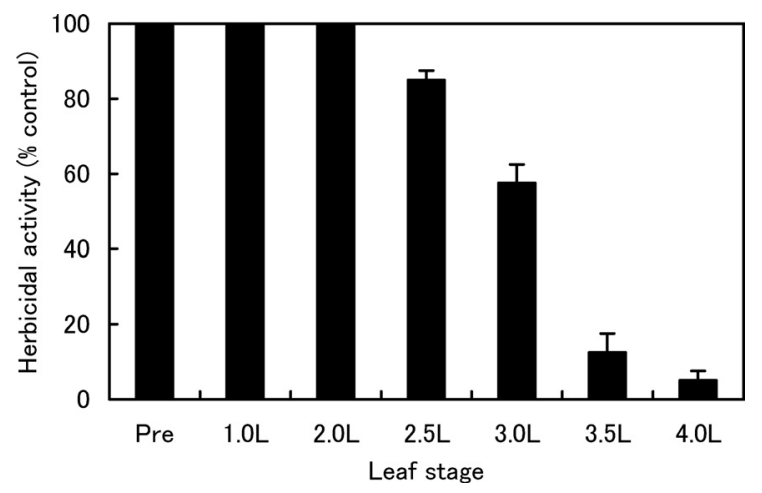

Fig. 2. Effect of leaf stage of barnyardgrass on herbicidal activity of MT-147. The dosage of MT-147 was $300 \mathrm{~g}$ a.i./ha. Vertical bars represent \pm S.E.

pre-emergence through the 2.0-leaf stage, MT-147 completely controlled the weed at $300 \mathrm{~g}$ a.i./ha. On the other hand, the activity decreased when applied at the 2.5-leaf stage, and only very low activity was observed at the 3.5- to 4.0-leaf stage.

Then effect of the water depth was examined between 1 and $6 \mathrm{~cm}$, and it was found that the herbicidal activity of MT147 was not affected (data not shown). Herbicidal activity (\% control) was $100 \%$ at $300 \mathrm{~g}$ a.i./ha at all water depths, and it was between $80 \%$ and $90 \%$ at $50 \mathrm{~g}$ a.i./ha. There was no significant difference in herbicidal activity among these water depths. Some other herbicides are reported to exhibit higher activity under deeper water conditions. ${ }^{10,13,14)}$ Those herbicides are probably absorbed through foliage, resulting in higher efficacy in deeper water. This result suggests that foliar absorption is not important for MT-147 to exhibit herbicidal activity in barnyardgrass.

The seeding depth of barnyardgrass affected the herbicidal activity of MT-147 (Fig. 3). When seeds were sown on the soil surface or $1 \mathrm{~cm}$ deep, MT-147 exhibited more than $80 \%$ control at 50 to $500 \mathrm{~g}$ a.i./ha. However, the compound controlled barnyardgrass by only $50 \%$ or less at 50 to $100 \mathrm{~g}$ a.i./ha when the seeding depth was $3 \mathrm{~cm}$, which indicates that the herbicidal activity of this compound is lower against barnyardgrass emerging from deeper soil. The MT-147 dosage of

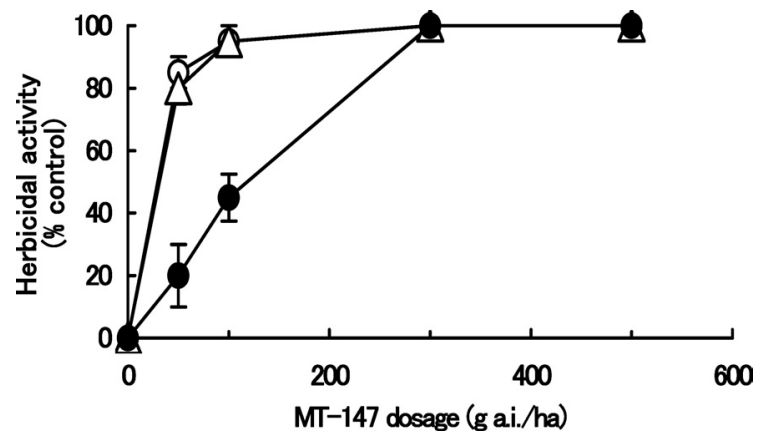

Fig. 3. Effect of seeding depth of barnyardgrass on herbicidal activity of MT-147. Seeding depth: $\bigcirc, 0 \mathrm{~cm}$ (soil surface); $\triangle, 1 \mathrm{~cm} ; \boldsymbol{\bullet}$ $3 \mathrm{~cm}$. Vertical bars represent \pm S.E.

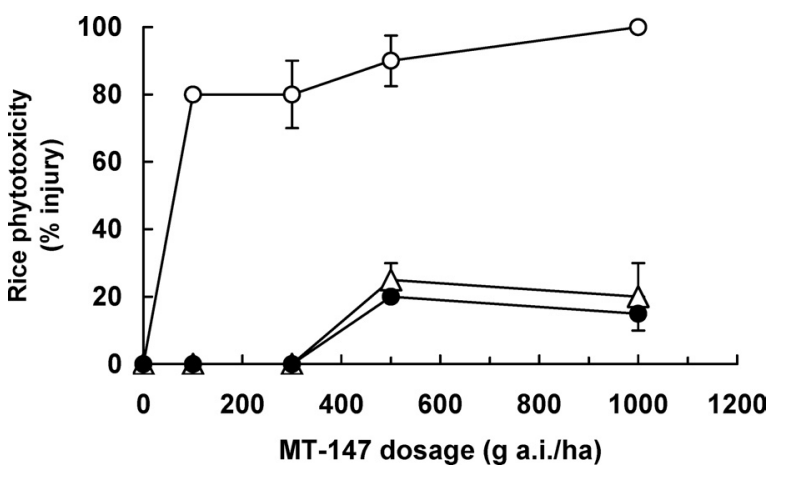

Fig. 4. Effect of transplanting depth of rice on phytotoxicity of MT-147. Transplanting depth: $\bigcirc, 0 \mathrm{~cm}$ (soil surface); $\triangle, 1 \mathrm{~cm} ; \boldsymbol{O}, 2.5$ $\mathrm{cm}$. Vertical bars represent \pm S.E.

$300 \mathrm{~g}$ a.i./ha was necessary to control the weeds seeded at a depth of $3 \mathrm{~cm}$.

In addition to these factors, the temperature and soil type also affected the herbicidal activity of MT-147. In general, activity tended to decrease at lower temperatures such as 15 to $25^{\circ} \mathrm{C}$ rather than higher temperatures such as 25 to $35^{\circ} \mathrm{C}$ (data not shown). Activity was lower in fine soils compared to coarse soils (data not shown).

\section{Phytotoxicity to rice}

The phytotoxicity of MT-147 to rice was also affected by the transplanting depth (Fig. 4). When rice seedlings were transplanted 1.0 or $2.5 \mathrm{~cm}$ deep, MT-147 caused no injury to rice at $300 \mathrm{~g}$ a.i./ha. On the other hand, the compound caused significant rice injury even at $100 \mathrm{~g}$ a.i./ha when the transplanting depth was $0 \mathrm{~cm}$. The transplanting depth is important in regard to the phytotoxicity of this compound, whereas the water depth was not influential (data not shown). These results suggest that MT-147 is mainly absorbed through plant roots to exhibit phytotoxicity or herbicidal activity. If root absorption is the main path for plant uptake, water leakage seems to be another important factor affecting phytotoxicity or herbicidal activity. This should be investigated as a future subject.

\section{Effect of bromobutide}

As MT-147 exhibits sufficient herbicidal activity only against barnyardgrass and some annual broadleaved weeds in rice paddy fields, it is necessary to broaden its herbicidal spectrum by applying with other herbicide(s) to confer a practical value. It was found that bromobutide was one of the herbicides suitable for the combination with MT-147. Bromobutide ${ }^{7)}$ is a herbicide effective for Scirpus juncoides control, and is used in one-shot herbicides. This herbicide increased the activity of MT-147 against barnyardgrass as well as broadening its herbicidal spectrum. When MT-147 was singly applied to barnyardgrass at the 2.5- or 3.0-leaf stage, the control \% was only 50 to $80 \%$ (Fig. 5); however, when MT-147 was applied with bromobutide ( $900 \mathrm{~g}$ a.i./ha), the activity significantly increased, exhibiting almost $100 \%$ control. Bromobutide itself 


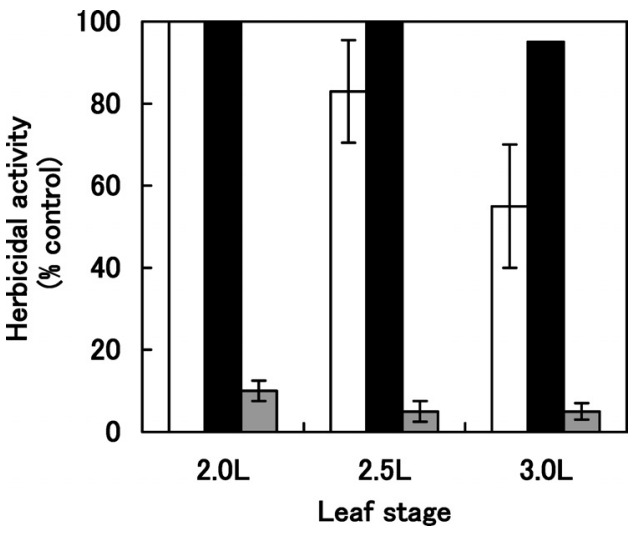

Fig. 5. Effect of bromobutide on herbicidal activity of MT-147. $\square$, MT-147 (300 g a.i./ha); $\mathbf{~ , ~ M T - 1 4 7 ~ ( 3 0 0 ~ g ~ a . i . / h a ) + b r o m o b u t i d e ~}$ ( $900 \mathrm{~g}$ a.i./ha); $\square$, bromobutide ( $900 \mathrm{~g}$ a.i./ha). Vertical bars represent \pm S.E.

had almost no herbicidal activity on barnyardgrass at this rate. As mentioned above, the herbicidal activity of MT-147 varied depending on soil types. The effect of bromobutide on increasing MT-147 activity was observed in several soils (data not shown). Bromobutide did not increase the phytotoxicity of MT-147 to rice when the transplanting depth was 1 or $2.5 \mathrm{~cm}$ (data not shown).

The mechanism of increase in herbicidal activity of MT147 by bromobutide is still unknown. When one compound increases the herbicidal activity of another compound, those compounds affect plants biochemically or physiologically by increasing the active compounds reaching the site of action through the alternation of absorption, translocation or metabolism. ${ }^{15)}$ In order to conjecture the mechanism which increases MT-147 activity by bromobutide, the contact period of barnyardgrass with compounds necessary for complete death was examined. When barnyardgrass was treated singly with MT-147 for 1 or 2 days and transferred to a water culture, the weeds were not completely killed (control \% was 50 to $80 \%$ )

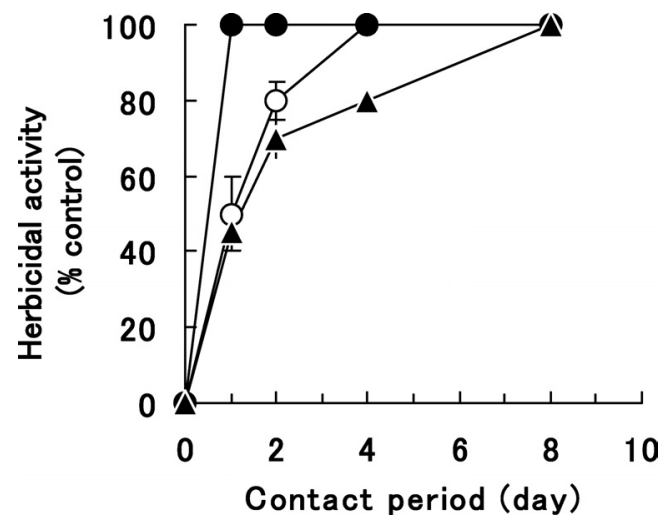

Fig. 6. Effect of contact period of barnyardgrass with compounds on herbicidal activity. O, MT-147 (300 g a.i./ha); O, MT-147 (300 g a.i./ha)+bromobutide (500 g a.i./ha); $\mathbf{\Delta}$, mefenacet (1000 g a.i./ha). Vertical bars represent \pm S.E.
(Fig. 6), but they were completely killed when treated with the compound for 4 days or more. On the other hand, when barnyardgrass was treated with MT-147 and bromobutide at the same time, the contact period necessary for complete death was one day. These periods were shorter than that of mefenacet, which completely killed barnyardgrass with a contact period of 8 days in this experiment. This result indicates that bromobutide shortened the contact period necessary for the complete death of barnyardgrass. Bromobutide might have promoted the absorption of MT-147 or decreased the metabolism rate of this compound, resulting in an increased amount of MT-147 reaching the site of action. Further investigation is necessary to clarify the mechanism which increases the herbicidal activity by bromobutide.

The site of action of MT-147 has not been determined so far. The symptoms of barnyardgrass treated with MT-147 are growth delay, subsequent chlorosis and necrosis, followed by complete death. Further investigation is necessary to clarify its mode of action.

In conclusion, a novel TFB, MT-147, has excellent herbicidal activity against barnyardgrass, and its activity was enhanced by bromobutide.

\section{References}

1) K. Arai, M. Ooka, F. Koizumi, S. Koda, Y. Iwasaki and Y. Kanemoto (Mitsui Touatsu Chemicals, INC.): Eur. Pat. Appl. EP 572001 (1993).

2) K. Arai, F. Koizumi, H. Suzuki, T. Kakimoto and S. Koda (Mitsui Touatsu Chemicals, INC.): Eur. Pat. Appl. EP 755935 (1995).

3) T. Kakimoto, F. Koizumi, K. Hirase and K. Arai: Abstract for Proc. 19th Asian-Pacific Weed Sci. Soc. Conf., Philippines, pp. 694-700 (2003).

4) T. Kakimoto, F. Koizumi, K. Hirase, S. Banba, E. Tanaka and K. Arai: Pest. Manag. Sci. 60, 493-500 (2004).

5) T. Kakimoto, F. Koizumi, K. Hirase and K. Arai: J. Pestic. Sci. 31, 380-389 (2006)

6) H. Shibayama: Weed Biol. Manag. 1, 53-60 (2001).

7) H. Matsumoto, N. Hino, A. Mine and M. Sakai: Weed Res. Japan 31, 273-279 (1986) (in Japanese with English summary).

8) M. Ogasawara, M. Konnai, T. Takematsu, S. Kato and M. Ishizaki: Weed Res. Japan 34, 138-145 (1989) (in Japanese with English summary).

9) K. Tsukuda, M. Murakami, H. Morinaka, K. Tsuzuki, N. Ichizen, M. Konnai and T. Takematsu: Weed Res. Japan 38, 175-181 (1993) (in Japanese with English summary).

10) K. Hirase, D. Kishi, M. Sakakibara, M. Nishida, K. Moriyasu and K. Ishikawa: Weed Res. Japan 40, 293-298 (1995).

11) K. Fujita and H. Shibayama: Weed Res. Japan 33, 278-284 (1988) (in Japanese with English summary).

12) Y. Ohta, K. Yamamoto and M. Deguchi: Jpn. J. Soil Sci. Plant Nutr. 41, 19-26 (1970) (in Japanese).

13) K. Hirase, S. Shimono and T. Asano: Weed Res. Japan 39, 249-255 (1994).

14) K. Hirase and W. T. Molin: Weed Biol. Manag. 2, 116-119 (2002).

15) K. K. Hatzios and D. Penner: Rev. Weed Sci. 1, 1-63 (1985). 